\title{
NGS data management and analysis for hundreds of projects: Experiences from Sweden
}

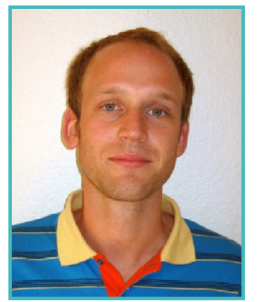

\section{Ola Spjuth}

Uppsala University, Uppsala, Sweden

Spjuth $O$ (2014) EMBnet.journal 20(Suppl A), e761. http://dx.doi.org/10.14806/ej.20.A.761

UPPNEX is a national e-infrastructure for next-generation sequencing data storage and analysis in Sweden. This presentation features strategic decisions made regarding hardware, software, maintenance and support, resource allocation, and illustrate challenges such as managing data growth in a shared system with over 400 research projects of varying types. Insights into bioinformatics usage patterns are also presented, to- gether with the ongoing development to extend the e-infrastructure with redundant resources, a secure system for analyzing sensitive data, and a private cloud.

\section{References}

Lampa S, Dahlö M, Olason PI, Hagberg J, Spjuth O (2013) Lessons learned from implementing a national infrastructure in Sweden for storage and analysis of next-generation sequencing data. Gigascience, 2:9. http://dx. doi. org/10.1186/2047-217X-2-9 